\title{
Study of Seasonal Variation in Snake Bite Patients Admitted To a Mangalore Based Tertiary Care Hospital
}

\author{
Ali $\mathrm{MQ}^{1}$, George $\mathrm{P}^{2}$, Bhat $\mathrm{KS}^{3}$ \\ ${ }^{I}$ Post Graduate Resident,Father Muller Medical College, Mangalore. \\ ${ }^{2}$ Professor Of Medicine,Father Muller Medical College,Mangalore. \\ ${ }^{3}$ Professor Of Medicine,Father Muller Medical College,Mangalore.
}

\begin{abstract}
:
Objective- The study was conducted to assess a seasonal pattern of patients attending the emergency services following history of a snake bite. Materials and Methods: It was aprospective study of 60 snake bite patients who presented to the Emergency services of a tertiary care hospital in Mangalore. The study was carried out over a period of two years. Data was collected by recording the date, time, and the history regarding the circumstances that led to the bite. A clinical examination of the site of bite and a systemic examination was carried out. The information was captured to a preformatted data sheet. Data was analysed using mean, frequency and percentage. Results: It was observed that 53.8\% of the affected patients were involved in agricultural activity.The bite was observed in the left lower limb in 34.8\% of the cases. An increased incidence of snakebite was found during the months of May to November as 70 percent of the bites were observed during this period. Patients were more susceptible to snake bite after the evening hours as 55\% of the bites were observed between 6:00pm to 12:00 am.
\end{abstract}

Conclusion: An increased incidence of snake bite is observed during the later part of monsoon.

Keywords: Snake bite, Seasonal variation, site of bite

\section{Introduction}

The four important species of venomous or the "big four" snakes are the Cobra, Russell's Viper, Saw Scaled Viper and the Krait.Majority of IndianvenomousSnakes are known to be active during the monsoon and in darkness ${ }^{1}$.The season also coincides with the period that the snakes lay their eggs ${ }^{1}$. This poses a particular risk of bite to farmers as they venture to the fields during the monsoon ${ }^{2}$. Snake bite is an important cause of morbidity and mortality in the tropics. The mortality following venomous snake bite is found to be 10,000 per year in India ${ }^{3}$. It was observed that there was an increased incidence of snake bite during the monsoon at other centers. The study was hence carried out to assess a seasonal pattern of snake bite in patients attending the emergency services at our hospital. The time of the day when a patients was most susceptible to bite and the most common site of bite was also assessed in the study. The data can prove to be valuable as educating the public of the increased threat during this period may help in reducing the incidence of snake bite by adopting preventive strategies.

Materials and Methods-The study was conducted at a tertiary care hospital based in Mangalore. It was a prospective cohort study conducted from May 2011 to June 2013. Consent of the patient was taken. Patients presenting with an alleged history of snake bite or an unknown bite presenting with signs of local and systemic envenomation were included into the study. An accurate history regarding the date, time of bite and the circumstances leading to the bite was obtained. The clinical examination comprised of a local examination to look for fang marks and other signs of systemic envenomation such as bleeding,swelling,ecchymosis and cellulitis. An examination of the cardiovascular, respiratory, gastrointestinal and nervous system was also carried out to look for signs of systemic envenomation. The information was captured to a preformatted data sheet.Data was analyzed using frequency mean percentages.

\section{Results}

A total of 60 patients [ 35 males and 25 females] were included into the study during the period. The mean age of the patients affected was $38.6 \pm 15.794$ years.

\section{Seasonal observation}

Most bites (70\%) were recorded during the months of May to November which constitutes the monsoon. An increase in the number of bites was observed towards the later part of monsoonbetween September to November. 


\begin{tabular}{|l|l|}
\hline Month & $\begin{array}{l}\text { Number of } \\
\text { Bites }\end{array}$ \\
\hline January & 5 \\
\hline February & - \\
\hline March & 3 \\
\hline April & 5 \\
\hline May & 9 \\
\hline June & 5 \\
\hline July & - \\
\hline August & 4 \\
\hline September & 6 \\
\hline October & 9 \\
\hline November & 9 \\
\hline December & 5 \\
\hline
\end{tabular}

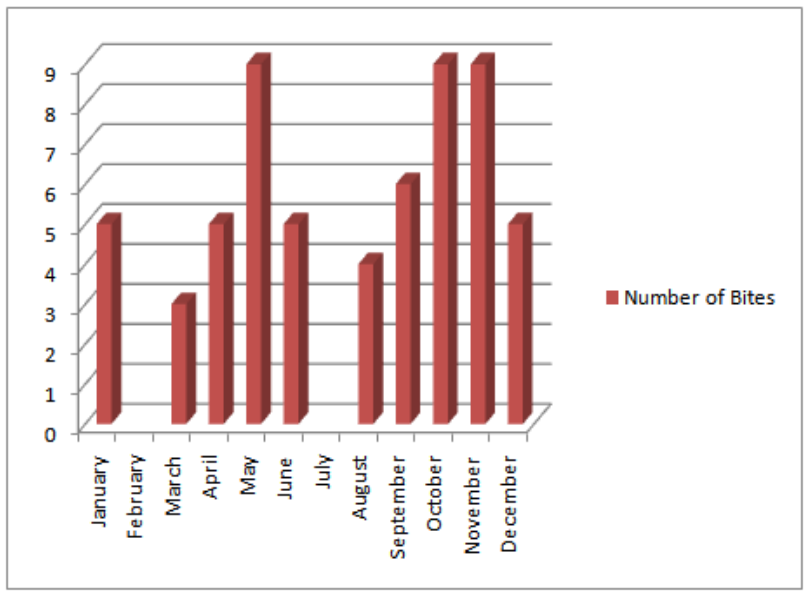

Timing of the bite- The incidence of snake bites was found to be most between $6 \mathrm{pm}$ and $12 \mathrm{am}$

\begin{tabular}{|l|l|}
\hline Time & Number of bites \\
\hline 12AM-5:59AM & 7 \\
\hline 6AM-11:59PM & 7 \\
\hline 12PM-5:59PM & 14 \\
\hline 6:00PM-11:59PM & 32 \\
\hline
\end{tabular}

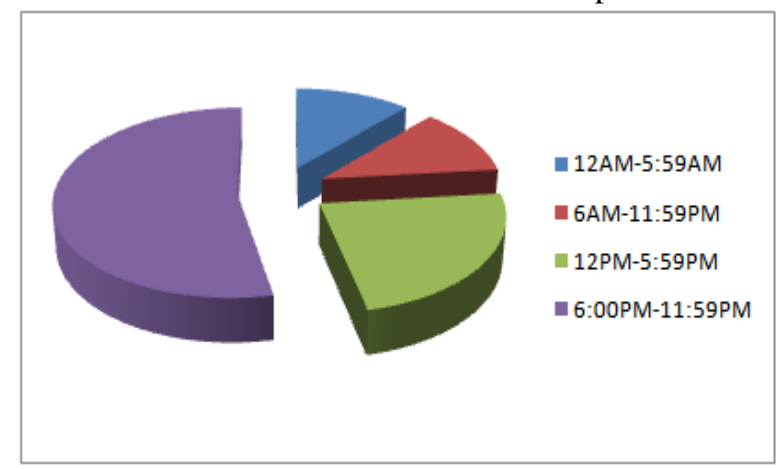

Site of Bite-The lower limbs were found to be the most common site of bite with most bites observed on the dorsum of the left foot (20\%) followed by the dorsum of the right foot $(13.3 \%)$. The other common site of bites were found to be the left index finger( $(8.3 \%)$,the Left toe( $6.6 \%)$ and the left heel(6.6\%).

\begin{tabular}{|l|l|}
\hline Site of bite & frequency \\
\hline LT Foot Dorsum & $20 \%$ \\
\hline LT Toe & $6.6 \%$ \\
\hline LT Ankle Lateral & $6.6 \%$ \\
\hline LT Heel & $6.6 \%$ \\
\hline LT Foot lateral & $1.6 \%$ \\
\hline LT Foot Medial & $1.6 \%$ \\
\hline RT Foot Dorsum & $13.3 \%$ \\
\hline RT Foot Lateral & $5 \%$ \\
\hline RT Ankle Medial & $3.3 \%$ \\
\hline RT Ankle Lateral & $3.3 \%$ \\
\hline RT Foot Medial & $1.6 \%$ \\
\hline RT Toe & $3.3 \%$ \\
\hline RT Little Toe & $3.3 \%$ \\
\hline RT Arm Medial & $1.6 \%$ \\
\hline RT Hand Dorsum & $1.6 \%$ \\
\hline RT Thumb & $3.3 \%$ \\
\hline RT Index finger & $1.6 \%$ \\
\hline LT Middle finger & $3.3 \%$ \\
\hline LT Hand Dorsum & $1.6 \%$ \\
\hline LT Index Finger & $8.3 \%$ \\
\hline
\end{tabular}

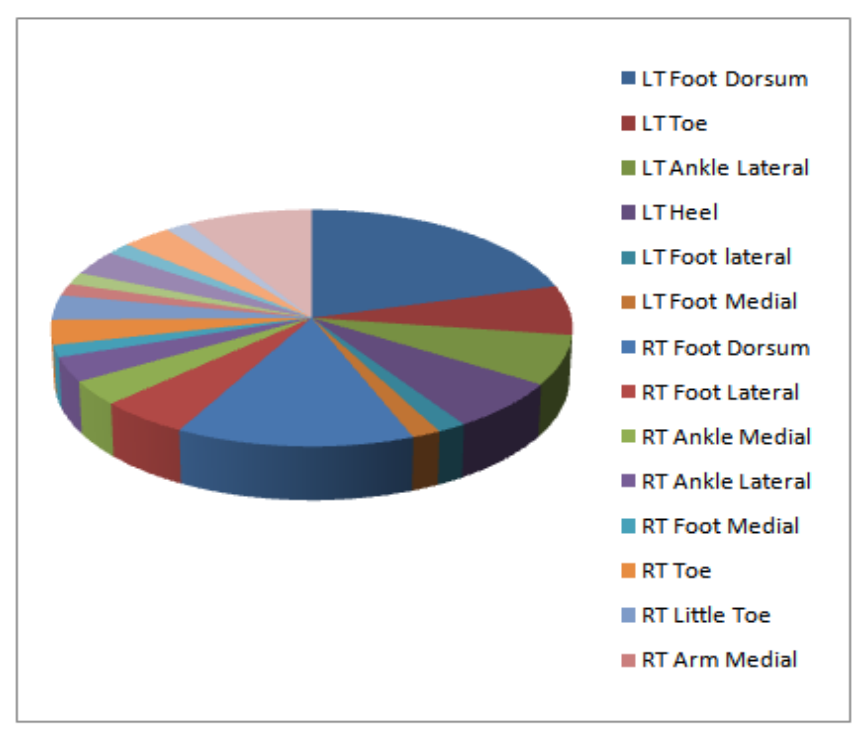

\section{Discussion}

The present study consisted of 60 subjects. The male preponderance observed in our study and the age group affected is in close correlation with studies conducted at other centers ${ }^{4,5}$.This may be attributed to their lifestyles involving outdoor activities or occupation as farmers ${ }^{6}$. 
Most bites in our study were observed during the months of May to November which represents the monsoon. Snakes are known to be more active during this season. ${ }^{1,2}$ This poses increased risk to farmers as they venture out to the fields to harvest their crops. Studies conducted at other centers also noticed a similar increase in the incidence of snake bites during the monsoon when compared to the drier summer ${ }^{7,8}$.

It was observed that patients were more susceptible to the threat of snake bite during darkness as $53.3 \%$ of the bites were observed between 6:00PM and 11:59AM. Other studies also reported an increased incidence of snake bite in the evening hours ${ }^{6,9}$.It coincides with the period when snakes are active in search of prey. ${ }^{1}$ This may explain the increased risk of snake bite during the period.

Most bites in our study were observed in the lower limbs. This could be as a result of walking bare foot and accidental stepping on a snake in view of poor visibility during the evening hours. Comparison with other studies also showed that patients carried an increased risk of snake bite to the lower limbs 6,9

Snake bite asan occupational disease becomes particularly important as $70 \%$ of the Indian population is involved in agriculture ${ }^{2.10}$. Farmers and individuals involved in outdoor activities should be educated regarding the preventive strategies of snake bite ${ }^{2}$. Education regarding the identification of snakes and prevention of bite has resulted in better outcomes in the form of reduced incidence of bites and mortality at other centers. ${ }^{11}$ The WHO has identified snake bite as an important neglected tropical disease. ${ }^{2}$ Partnership between the health authorities and citizens can hence play an important role in reducing the burden of this potentially preventable condition.

\section{References}

[1] Daniel J C. The Book Of Indian Reptiles And amphibians. Mumbai:Oxford University Press 2002; 1: 74-75.

[2] Warrell D A. Guidelines For The Clinical Management Of Snake Bite In The South East Asia Region. Southeast Asian J Trop Med 2005; 30: 9-11.

[3] Chugh K S. Snake-bite-induced acute renal failure in India. Kidney Int 1989; 35: 891-907.

[4] Singh J, Bhoi S, Goel A. Clinical profile of venomous snake bites in north Indian Military Hospital. J Emerg Trauma shock 2008; 1: $78-80$

[5] Patil TB, Bansod YV, Patil MB. Snake Bite Induced Acute Renal Failure: A study of clinical profile and predictors of poor outcome. World J NephrolUrol 2012; 1: 59-65.

[6] Saravu k, Somavarapu V, Shastry AB, Kumar R. Clinical profile, Species-specific severity grading, and outcome determinants of snake envenomation: An Indian tertiary care hospital-based prospective study. Indian J Crit Care Med 2012; 16: 187-92.

[7] Brunda G, Shashidhar R B. Epidemiological Profile Of snake Bite Cases From Andhra pradesh using Immunoanalytical Approach. Indian J Med 2007; 125: 661-5.

[8] Kularatne SAM. Epidemiology and clinical picture of the Russell's viper (DaboiaRusselliiRusellii) bite in Anuradhapura, Srilanka: A prospective study of 336 patients. Southeast Asian J Trop Med Public Health 2003 ; 34: 855-62.

[9] Jarwani B, Jadav P, Madaiya M. Demographic epidemiologic and clinical profile of snake bite cases presented to Emergency Medicine department, Ahmedabad, Gujarat.J Emerg Trauma Shock 2013; $6: 199-202$.

[10] The World Bank. India: priorities For Agriculture and Rural Development. http:// web worldbank.org/ (accessed 19 sept 2013)

[11] Pandey DP, Thapa CL, Hama PK. Impact of first aid treatment in management of snake bite victims in Madi Valley. J Nepal Health Res Counc. 2010; 8: 5-9 